\title{
Effect of Different Mulch on Growth and Yield of Turmeric (Curcuma longa L.) on Drip Irrigation
}

\author{
Mukulkumar*, Swipnil Dubey, P.K. Dwivedi, R.S. Rahav, \\ L. Chakravarti and Mohitkumar
}

Krishi Vigyan Kendra, Raisen-464551, Madhya Pradesh, India

*Corresponding author

\begin{abstract}
A B S T R A C T
Keywords

Turmeric,

Mulching, Drip irrigation, Yield

Article Info

Accepted:

14 December 2017

Available Online:

10 January 2018

Field experiments were conducted on the Medium and shallow Black Soils at KVK, Raisen, Madhya Pradesh during 2015-2017 to determine the effect of different mulches on vegetative growth and yield of Turmeric on drip irrigation. The research trials for the consecutive two years showed that plastic mulch resulted maximum plant height $(116.140 \mathrm{~cm})$, No. of suckers/ plant (6.597), Length of leaves $(63.663 \mathrm{~cm})$, Width of leaves $(17.500 \mathrm{~cm})$, Days to maturity (266), No. of rhizome/ plant (19.35), Length of rhizome $(9.303 \mathrm{~cm})$, Diameter of rhizome $(3.367 \mathrm{~cm})$, Rhizome yield /plant $(530.413 \mathrm{~g})$, Rhizome yield/ha (318.0Q ha-1). The highest yield was observed under the plastic mulch $28 \%$ increase in yield as compared to without mulch $\left(248.2 \mathrm{Q}^{\mathrm{h}} \mathrm{a}^{-1}\right)$.

\section{Introduction}

The spices 'Turmeric' or 'Haldi' constitutes boiled, dried, cleaned and polished rhizome (the underground swollen modified stem of plant) of Curcuma longa Linn. Syn. $C$. domestica var. Belongs to the family Zinziberaceae and it is one of the important and ancient spices of India. It is considered to be a triploid with somatic chromosome number, $2 n=3 x=63$. Mulching is an important component in the management practices of turmeric. In the dry months, it conserves the moisture in the soil and enhances soil temperature for proper germination of the rhizome. In addition, physical properties of

soil and minimizing weed competition it checks weed growth as well as weeds between mulch strips can be controlled by an herbicide and enriches the fertility of the soil after decomposition. Further it prevents washing out of soil and nutrients during heavy rains (Randhawa and Nandpuri, 1969 and Mohanty 1977). Soil under plastic mulch remains loose, friable and well-aerated. Roots have access to adequate oxygen and microbial activity is excellent. Plastic mulch is practically impervious to carbon dioxide $\left(\mathrm{CO}_{2}\right)$, a gas that is of prime importance in photosynthesis. Very high levels of $\mathrm{CO}_{2}$ build up under the plastic, because the film does not allow it to escape. It has to come through the holes made
\end{abstract}


in the plastic for the plants and a "chimney effect" is created, resulting in localized concentrations of abundant $\mathrm{CO}_{2}$ for the actively growing leaves which increased the yield of turmeric.

\section{Materials and Methods}

The field experiment was conducted during the months of July to January in 2 years (2015-16 and 2016-2017) at the KVK, Raisen, Madhya Pradesh. India, located at $22^{0} 47^{\prime}-23^{0}$ $33^{\prime} \mathrm{N}$ latitude and $77^{0} 21^{\prime} \mathrm{E}-78^{0} 49^{\prime} \mathrm{E}$ longitude and the soil at the experimental field is a medium black. The field plot is divided in beds of equal size of $1 \times 4 \mathrm{~m}$ and each bed represented a single treatment. Turmeric (Var. Roma) was being planted in two rows on each bed with spacing of $0.3 \mathrm{~m}$ between plant to plant and $0.5 \mathrm{~m}$ between two rows. In between two treatments (i.e. two beds) $50 \mathrm{~cm}$ wide strips were left to minimize the chances of moisture movement from one treatment to another treatment. The experiments were laid out following the Randomized Block Design (RBD) with 4 treatments and 3 replications. The treatments were randomly applied to each block. The various treatments were as follows: T1: Silver color plastic mulch, T2: Buteamonosperma green leaves, T3: paddy straw, T4 without any mulch (control). The silver plastic film of $50 \mu$ thickness (200 gauge) were used as a treatment of mulch material. The drip irrigation system was installed and operated daily to provide the sufficient moisture to the plants. Standard agronomical practices such as fertilization and plant protection measures were applied during the entire crop period. A fertilizer dose of 100 $\mathrm{kg}$ each of $\mathrm{N}, \mathrm{P}$ and $\mathrm{K}$ ha-1 was applied in split doses. Fifty per cent of nitrogen and fifty per cent of phosphorous and potash were incorporated at the time of planting. The twenty five percent of $\mathrm{N}$, remaining fifty percent of $\mathrm{P}$ and $\mathrm{K}$ were applied at 60 days after planting (DAP). The rest 25 percent of nitrogen was applied at 90 DAP. For fertigation, water soluble fertilizers were applied through drip irrigation. Well rotten cow dung $\left(25 \mathrm{t} \mathrm{ha}^{-1}\right)$ was mixed in the beds before planting. The number of sprouts were counted from each plot at 50 DAP. Growth parameters were recorded in the first week of November. The crop was harvested in the first week of January and yield per hectare was estimated.

\section{Results and Discussion}

Treatment wise observations of the crop were recorded from July, 2015 to January, 2017. Table 1 shows the pooled values of attributes viz. plant height $(\mathrm{cm})$, no. of suckers per plant, length of leaves $(\mathrm{cm})$, width of leaves $(\mathrm{cm})$, days to maturity, number of rhizomes, length of rhizomes $(\mathrm{cm})$, diameter of rhizomes $(\mathrm{cm})$, rhizomes yield per plant (g) and rhizomes yield per hectare $\left(\mathrm{Qha}^{-1}\right)$ under different treatments. From the Table 1, it is revealed that the plastic mulch has the significant influence on plant growth and yield in comparison to Buteamonosperma, paddy straw and without mulch (control). Results showed highest value of plant height (116.140 $\mathrm{cm})$ was recorded in plastic mulch followed by in Buteamonosperma $(114.947 \mathrm{~cm})$. The use of paddy straw also resulted of increase in plant height $(113.090 \mathrm{~cm})$ over control $(112.770 \mathrm{~cm})$ (Fig. 1). The number of suckers per clump responded significantly to different mulching materials. The use of plastic mulch, Buteamonosperma, paddy straw, responded suckers per clump increased to that of control (Table 1 and Fig. 3). The highest number of suckers (6.59 nos.) was obtained in plastic mulch which was significantly different from control as well as other treatments. The lowest number of suckers (4.59) was recorded in without any mulch. The leave length and leave width was statistically significant in different treatments (Table 1; Fig. 2). The leave length and leave width were significantly higher in 
plastic mulch $(63.66 \mathrm{~cm}$ and $17.50 \mathrm{~cm})$ followed by Buteamonosperma and paddy straw mulch were $(61.87 \mathrm{~cm}, 61.42 \mathrm{~cm}$ and $15.30 \mathrm{~cm}, 15.06 \mathrm{~cm}$ respectively). While the results obtained the without any mulch (control) was $59.42 \mathrm{~cm}$ and $14.24 \mathrm{~cm}$ respectively. Similarly, results in Table 2 and Figure 3 showed that number of rhizomes per plant, length of rhizome $(\mathrm{cm})$ and width of rhizome $(\mathrm{cm})$ was significantly increased in plastic mulch (19.35, 9.30 and 3.36 respectively) followed by Buteamonosperma (14.54, 8.75 and 3.12 respectively) and paddy straw mulch (13.94, 8.56 and 2.58 respectively), whereas the yield component characters was decreased in without mulch (11.54, 7.49 and 2.49 respectively). The similar result was obtained by Vanlalhluna (2010); Kaur (2016) and Verma (2016) in turmeric.

Table.1

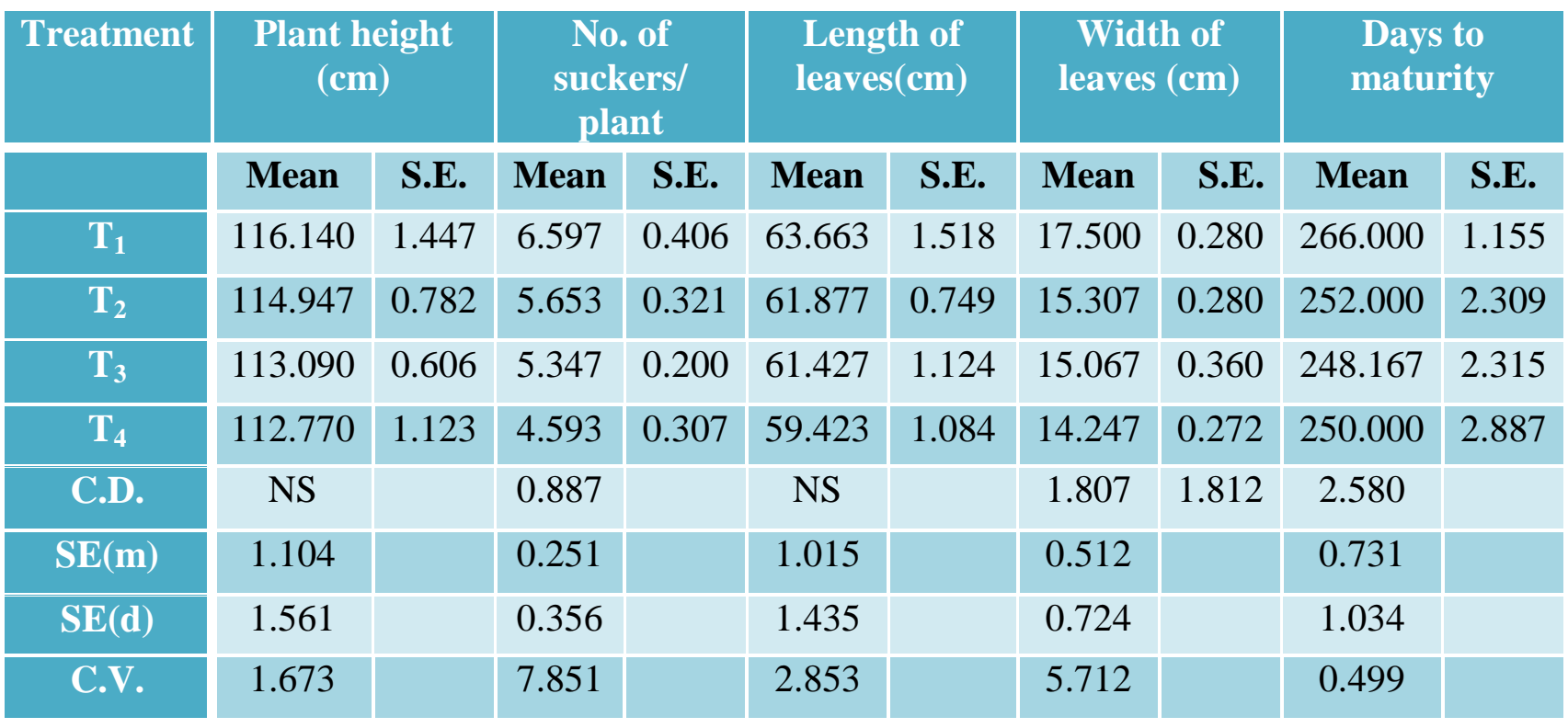

Table.2

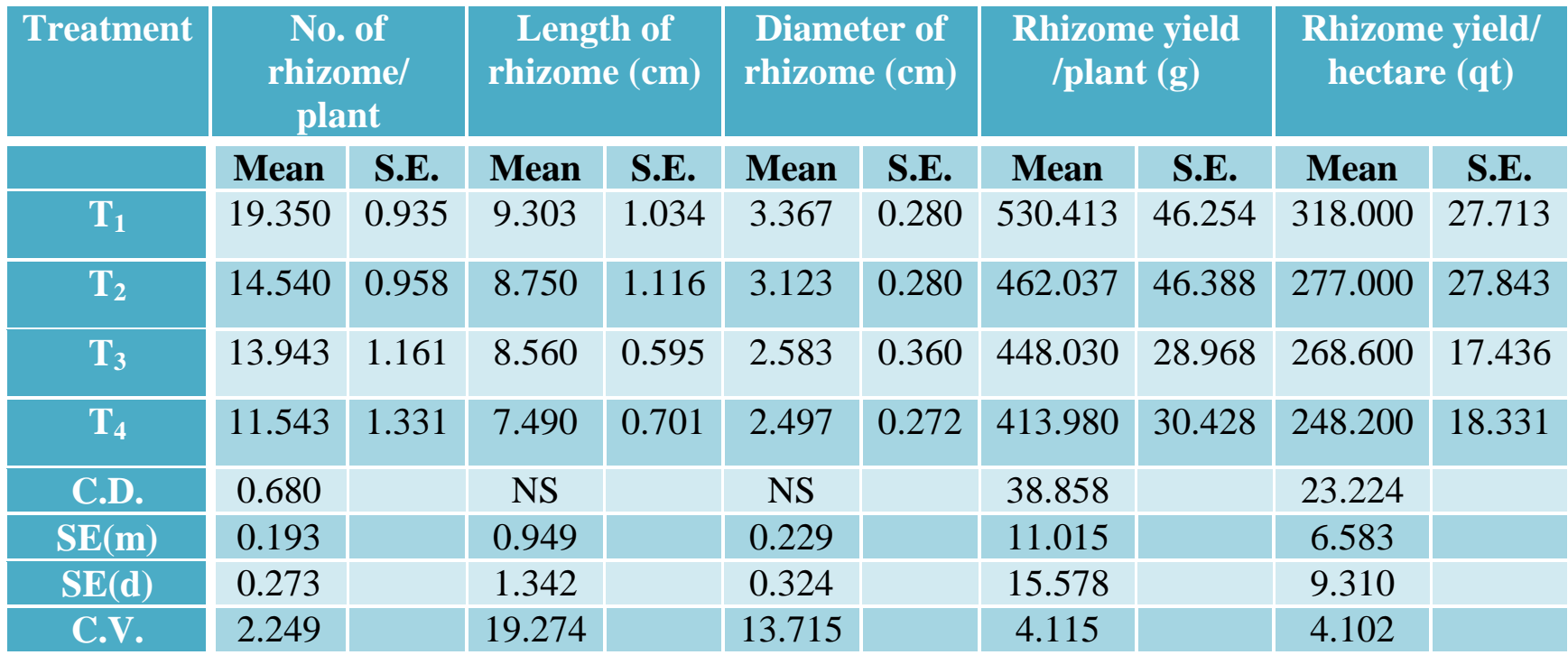


Fig.1

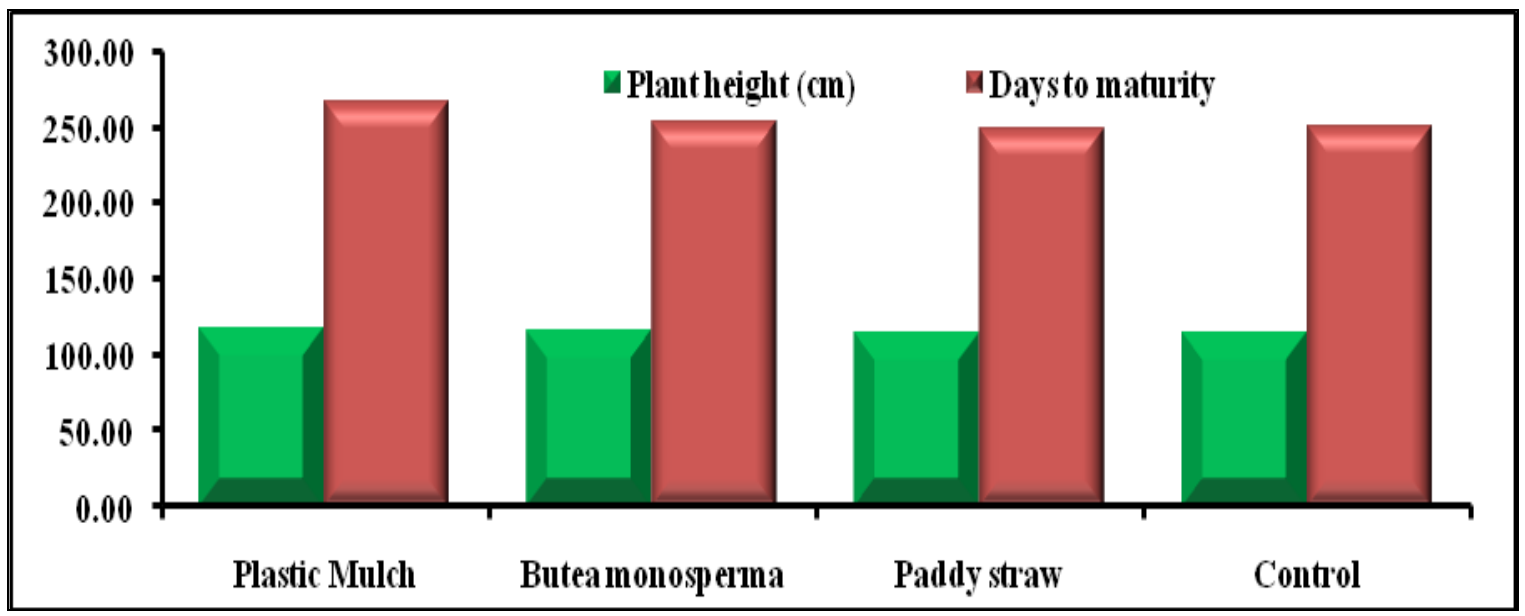

Fig.2

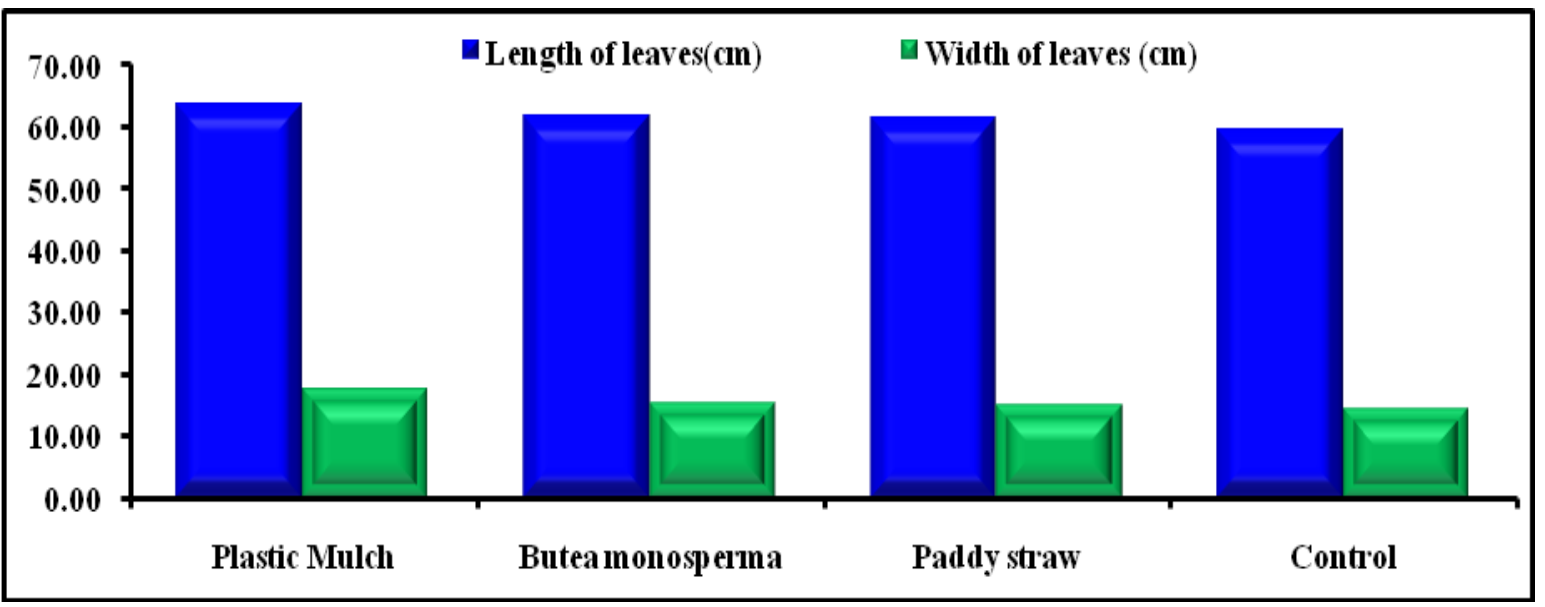

Fig.3

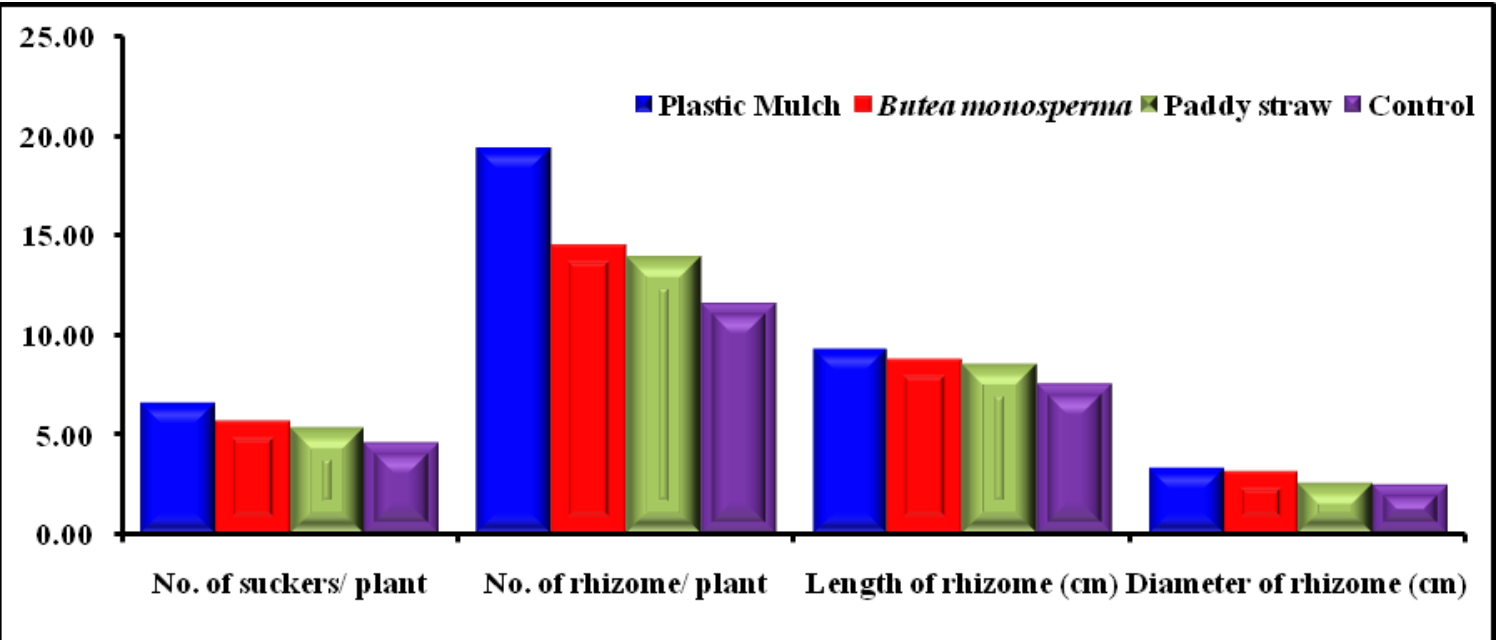


Fig.4

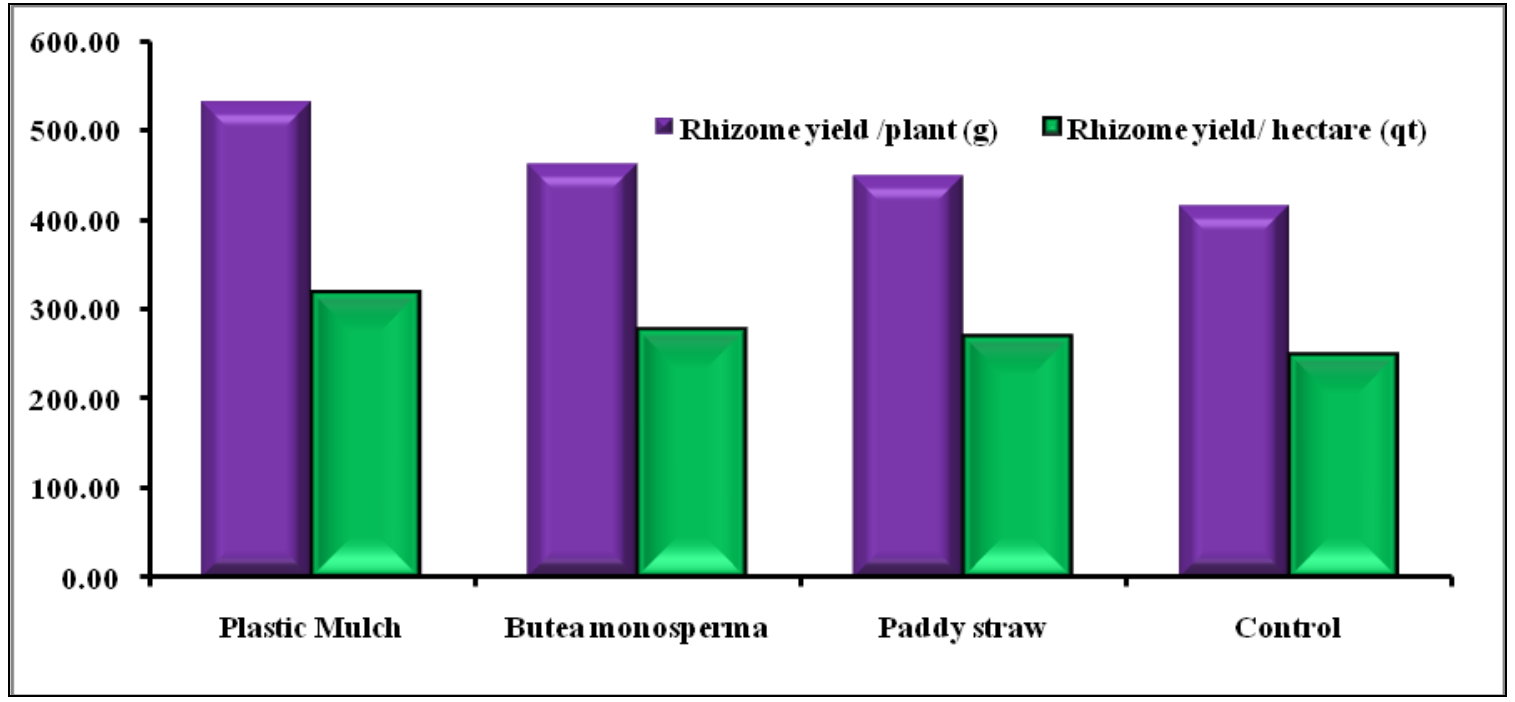

The results presented in Table 2 and Figure 4, clearly revealed that the yield per plant of turmeric was significantly influenced by the use of different mulching materials. Silver color plastic mulch produced pronounced effect with regard to plant yield against the other treatments in both the years. Use of paddy straw was less effective towards increasing the yield of the crop. However, the maximum and minimum yield of 530.41g and 413.98gper plant were recorded in silver color plastic mulch and control, respectively. The yield data presented in Table 2 shows that the yield of Turmeric crop was also statistically significant under different treatment. Maximum yield of (318 $\left.\mathrm{Qha}^{-1}\right)$ in plastic mulch followed by Butea monosperma and paddy straw mulched crop were (277 $\mathrm{Qha}^{-1}$ ) and 268.6 quintal per hectare, respectively. The yield was significantly low in control $\left(248.2 \mathrm{Qha}^{-1}\right)$. The increased growth as observed in the present investigation by the use of plastic mulch was due to uniform germination, conservation of soil moisture and better weeds control as compared to other treatments. The yield was always greater in case of plastic mulch treated plants. This could be due to greater nutrients and water availability to plants as compared to non- mulched condition the yield of Turmeric was estimated to be $28.12 \%$ more than the without mulch. Reddy (2017) reported that the yield was always greater in case of plastic mulch treated plants. Groszmann (1954) also reported uniform germination by mulching which corroborates with these findings. Also mulches facilitated in better mineralization and availability of nutrients in modifying the various yields attributes to the better advantage of rhizome yield.

\section{Acknowledgements}

The authors are thankful to the Krishi Vigyan Kendra Raisen-464551, Madhya Pradesh for providing the required research facilities.

\section{References}

Groszmann, H. M. 1954. Ginger production. Ad. Agric. J., 78: 259-62.

Kaur, A. and Brar A.S. 2016. Influence of mulching and irrigation scheduling on productivity and water use of Turmeric (Cucrcuma longa L.) in north-western India. Irrigation science, 34 (4): 261269.

Mohanty, D. C. 1977. Studies on the effect of 
different mulch materials on the performance of ginger in the hills of Pottangi. Orissa J. Hort., 5: 11-17.

Randhawa, K. S. and Nandpuri, K. S. 1969. Grow ginger in your kitchen garden. Prog. Fmg., 5 : 6-7

Reddy, A.R.G., Tiwari, K.N. and Santosh, D.T. 2017. Yield response of Turmeric (Curcuma longa L.) under drip fertigations and plastic mulch condition. Int.J.Pure App.Biosci. 5(4): 1265-1269.
Vanlalhluna, P.C., Sahoo, U.K., Lalremruati, J.H. 2010. Relative efficacy of different mulch type on soil moisture conservation and performance of rain fed turmeric in an agroforestry system of Mizoram. Range management and Agroforestry, 31(1): 31-35.

Verma, A. and Sarnaik, D.A. 2016. Effect of different type of mulches on growth and yield of turmeric (Curcuma longa L.). Internat. J. Agric. sci., 2(2): 425-426.

\section{How to cite this article:}

Mukulkumar, Swipnil Dubey, P.K. Dwivedi, R.S. Rahav, L. Chakravarti and Mohitkumar. 2018. Effect of Different Mulch on Growth and Yield of Turmeric (Curcuma longa L.) on Drip Irrigation. Int.J.Curr.Microbiol.App.Sci. 7(01): 1714-1719.

doi: https://doi.org/10.20546/ijcmas.2018.701.207 